\title{
VIBRATION MEASUREMENT OF THE SPring-8 STORAGE RING
}

\author{
K. Tsumaki, N. Kumagai, SPring-8, Hyogo, Japan
}

\begin{abstract}
Importance of vibration problems increases with the smaller emittance of a storage ring for synchrotron radiation source. Vertical emittance of the SPring- 8 storage ring is so small that effect of vibration to an electron beam can not be neglected. We thus studied the vibration of the SPring- 8 storage ring. Measurements of beam oscillation and magnet vibration were done and the relation between them was investigated. Vibration source and propagation paths were also studied and the suppression method is discussed.
\end{abstract}

\section{INTRODUCTION}

The SPring- 8 storage ring is the $8 \mathrm{GeV}$ third generation synchrotron radiation source with $1436 \mathrm{~m}$ circumference. The emittances of the storage ring are $6 \mathrm{~nm}$ for horizontal and $3 \mathrm{pm}$ for vertical[1]. Beam sizes for horizontal and vertical direction at insertion devices are $380 \mu \mathrm{m}$ and 4.5 $\mu \mathrm{m}$ respectively. The oscillation of an electron beam leads to a large growth of effective emittance due to the small beam sizes.

This effect becomes more serious with the emittance decrease as in the case of future low emittance light source. It is inevitable to study the beam oscillation, its causes and the suppression method to achieve the designed beam quality.

Though there are many causes for the beam oscillation, we focused the problems on the effect of magnet vibration. We measured the beam oscillation and magnet vibration and studied the relation between them. The source of magnet vibrations was also studied and suppression method of beam oscillation was discussed.

\section{BEAM OSCILLATION}

There are four button pickup position monitors along the beam line at every 12 cells to study the correlation between beams. We used these monitors for the measurement of beam oscillation. The signals from the monitors are fed to FFT analyzer and the spectrum was obtained as shown in Fig. 1 and Fig. 2.

The oscillation amplitude for horizontal is larger than vertical and the number of oscillation peaks of horizontal are larger than that of vertical. Integrated amplitudes of horizontal and vertical beam oscillation are $13 \mu \mathrm{m}$ and 7.3 $\mu \mathrm{m}$ respectively. Effective growth of horizontal and vertical emittance $\Delta \varepsilon / \varepsilon$ is thus $1.2 \times 10^{-3}$ and 1.2 respectively.

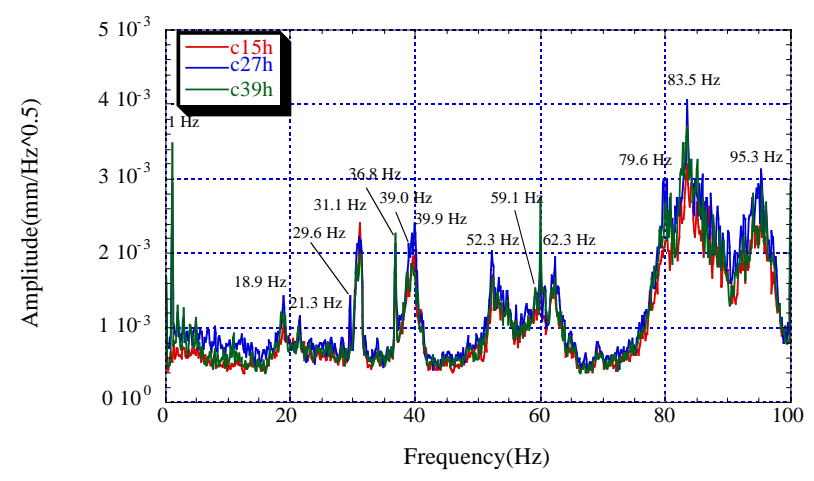

Fig. 1 Horizontal oscillation spectrum of electron beam.

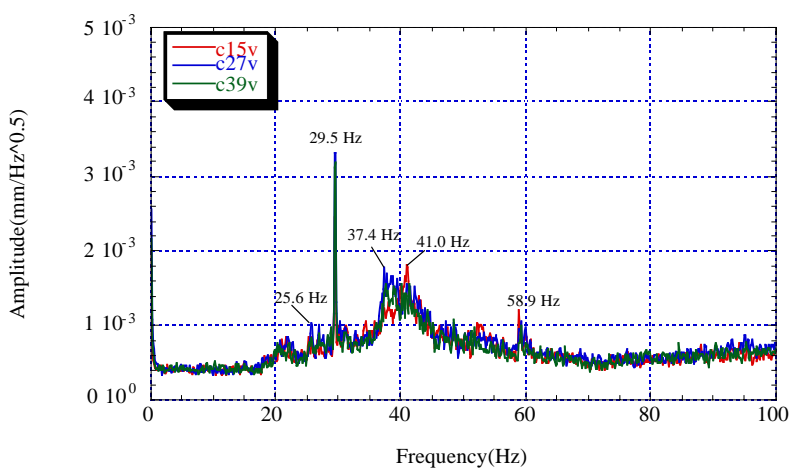

Fig. 2 Vertical oscillation spectrum of electron beam.

\section{MAGNET VIBRATION}

Vibration and the resonance frequencies of magnet and girder were measured to compare with the beam oscillation.

\subsection{Measurement of Magnet Vibration}

The SPring-8 storage ring has 48 cells and there are four electrical/mechanical buildings for air condition and water cooling near the cell 4, 16, 28 and 40. Machines for air condition and water cooling are the main sources of vibration in the SPring- 8 site. We measured the magnet vibration at cell 28 and cell 34 . Cell 28 is the nearest and cell 34 is the farthest cell to the machine room. 
The storage ring building is on hard rocks except a few places. Under the cell 9, there is an underpass leading to the inner area of the storage ring; there are rooms for wave guides under the floor at cell 3,15, 27, 41 where the RF cavities are placed. The storage ring has four $30 \mathrm{~m}$ long straight sections where girders are different from that of normal cell. At these special places the magnet vibration is expected to be different from normal cell vibration. We thus measured the magnet vibration at these special cells.

A normal cell consists of ten quadrupole, seven sextupole and two bending magnets. In a straight section cell there are six quadrupole magnets on a girder. We measured the vibration only for the quadrupole magnets because sextupole and bending magnets have no first order effects to beam oscillation. Measurements were done using the accelerometer (KOKU DENSHI JA-5VD1). Voltage signals were fed to the amplifier (KOKU DENSHI VM-5122) and FFT analyzer (ONO SOKKI CF360). In FFT analyzer acceleration is transformed to displacement.

Results for cell 9 are shown in Fig. 3. Frequencies of $18.9 \mathrm{~Hz}, 21.3 \mathrm{~Hz}, 29.6 \mathrm{~Hz}, 31.1 \mathrm{~Hz}, 39.0 \mathrm{~Hz}, 59.1 \mathrm{~Hz}$ that are observed in beam oscillation were identified in magnet vibration spectrum for horizontal direction. Frequencies of $25.6 \mathrm{~Hz}, 29.5 \mathrm{~Hz}, 58.9 \mathrm{~Hz}$ can be also identified in vertical spectrum. Similarly magnet vibration of other cells was searched; however, following peaks can not be identified.

- Horizontal direction: $1 \mathrm{~Hz}, 36.8 \mathrm{~Hz}, 52.3 \mathrm{~Hz}, 62.3$

$\mathrm{Hz}$ and frequencies of the range from $80 \mathrm{~Hz}$ to 100 $\mathrm{Hz}$.

- Vertical direction: frequencies around $40 \mathrm{~Hz}$.
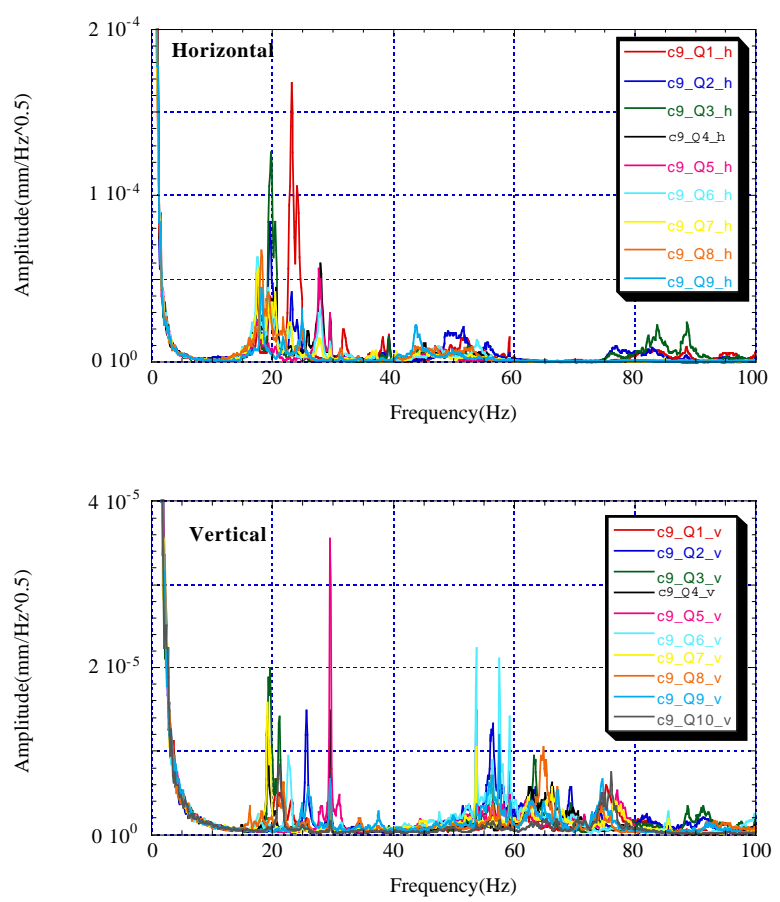

Fig. 3 Vibration spectrum of quadrupole magnets at cell 9.

\subsection{Measurement of Resonance Frequency of Magnet and Girder}

In a cell there are three types of girder named A, B, C and six types of quadrupole magnets named $\mathrm{a}, \mathrm{b}, \mathrm{c}, \mathrm{d}$, e and $\mathrm{f}$. On the A girder Q1, Q2, and Q3 and on the B girder Q4, Q5, Q6 and Q7 magnets are placed respectively. Remaining Q8, Q9, Q10 magnets are on the C girder. The cell has mirror symmetry and $\mathrm{A}$ and $\mathrm{C}$ girders have the same structure.

We measured the resonance frequency and oscillation modes for $\mathrm{A}$ and $\mathrm{B}$ girder and for six types of quadrupole magnets by hammering method. An accelerometer was set on a girder and a magnet and the several points were hammered. Signals from an accelerometer and a hammer were fed to amplifiers and the amplified signals were analyzed by FFT anlyzer. Transfer function was obtained in FFT analyzer.

We measured 11 horizontal and 7 vertical resonance frequencies for A and B girder below $100 \mathrm{~Hz}$. Similarly 30 horizontal and 19 vertical resonance frequencies of magnets were measured. For horizontal direction, three peaks in beam oscillation spectrum coincide with the magnet and girder resonance frequency. Beam frequency $18.9 \mathrm{~Hz}$ coincide with the resonance frequency $19.0 \mathrm{~Hz}$ of c, e, f type magnets and $\mathrm{B}$ girder; $21.3 \mathrm{~Hz}$ of beam frequency corresponds to the $21.0 \mathrm{~Hz}$ resonance frequency of $\mathrm{b}$, e type magnets and $\mathrm{B}$ girder and $21.5 \mathrm{~Hz}$ of $\mathrm{f}$ type magnet; $52.3 \mathrm{~Hz}$ corresponds to $52.3 \mathrm{~Hz}$ of A girder, 52.5 $\mathrm{Hz}$ of a type and $52.0 \mathrm{~Hz}$ of d type resonance frequency. For vertical direction there is no corresponding peak in beam oscillation spectrum.

\subsection{Effect of Cooling Water}

Main vibration source is the machines in the electrical/mechanical room that consists of air conditioner room and cooling water room. We measured the contribution of each room and found that the effect of cooling water room is dominant. Next we investigated how the pump vibration in cooling water room is propagated to the magnets. Two main propagation routes are considered; One is that the cooling water that flows in the magnet coils vibrates the magnets directly; next is the vibration from pumps propagated in the floor. To investigate which contribution is more dominant, we stopped the cooling water flow by closing the valves just before and after the magnets. Horizontal vibration of magnets decreases drastically when the water flow was stopped as shown in Fig. 4. Amplitude reduces to $29 \%$. Contrary to the horizontal case, vertical magnet vibration does not change. This results shows us that the horizontal vibration of magnets is originated from cooling water which flows in the coils of magnets and the vertical vibration are due to the vibration propagated in the floor from cooling water room. 

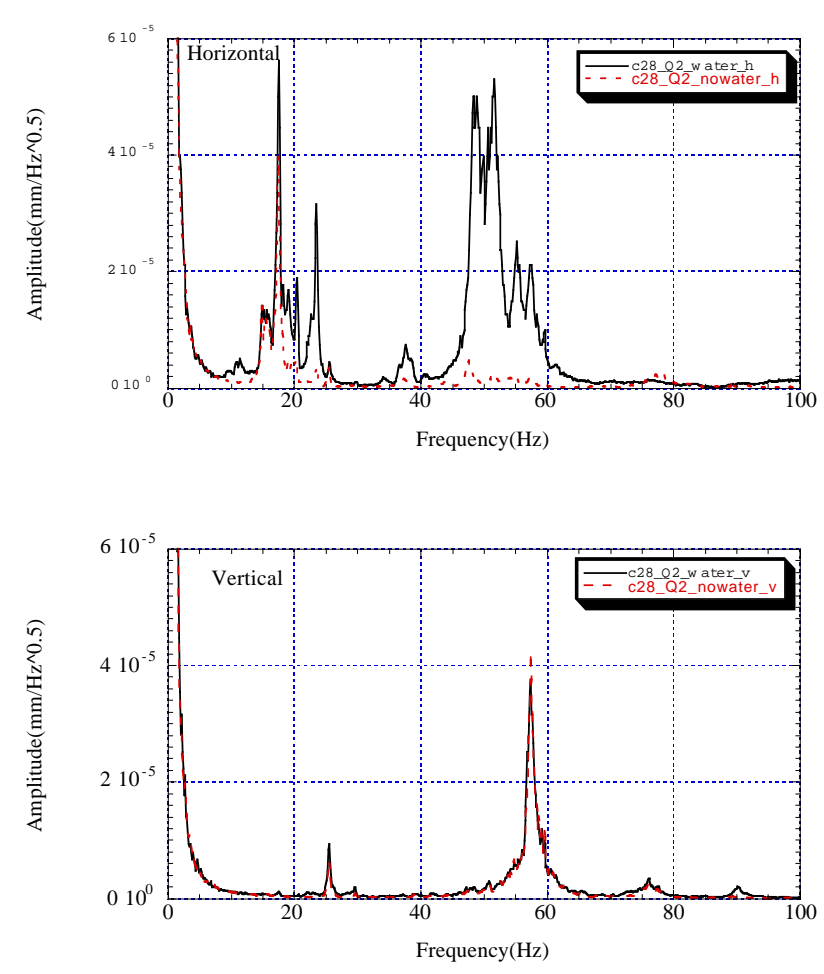

Fig. 4 Horizontal and vertical magnet vibration spectrum with and without water flow in magnet coils.

\section{UNIDENTIFIED OSCILLATION}

Identified frequencies in horizontal beam oscillation are $18.9 \mathrm{~Hz}, 21.3 \mathrm{~Hz}, 52.3 \mathrm{~Hz}$ which are equal to the resonance frequency of magnet and girder and $29.6 \mathrm{~Hz}$ and $59.1 \mathrm{~Hz}$ which are the pump frequencies and $29.6 \mathrm{~Hz}$, $31.1 \mathrm{~Hz}, 39.0 \mathrm{~Hz}, 39.9 \mathrm{~Hz}$ which are observed in magnet vibration. Unidentified frequencies are $1 \mathrm{~Hz}, 36.8 \mathrm{~Hz}, 62.3$ $\mathrm{Hz}$ and $80 \mathrm{~Hz}$ to $95 \mathrm{~Hz}$. In vertical beam oscillation 29.5 $\mathrm{Hz}$ and $58.9 \mathrm{~Hz}$ is the vibration propagated in the floor from the cooling water pump. Unidentified frequency is around $40 \mathrm{~Hz}$.

Frequencies around $90 \mathrm{~Hz}$ for horizontal and $40 \mathrm{~Hz}$ for vertical are not the narrow peak but the wide one. Number of betatron oscillation in a cell is 1.193 for horizontal and 0.537 for vertical. This corresponds to the wavelength of $25.1 \mathrm{~m}$ and $55.65 \mathrm{~m}$. If the wavelength of betatron oscillation and the wavelength of vibration propagated in the floor coincide, the Fourier component of error distribution due to vibration around betatron tune becomes large and amplitude of beam oscillation increases. If we assume $2200 \mathrm{~m} / \mathrm{s}$ as the propagation velocity[2], the resonating frequencies are $88 \mathrm{~Hz}$ for horizontal and $40 \mathrm{~Hz}$ for vertical. Accordingly we can considered the peaks around $90 \mathrm{~Hz}$ for horizontal and $40 \mathrm{~Hz}$ for vertical are due to the coincidence of wavelength of vibration and betatron oscillation and the resultant growth of beam amplitudes.
Frequencies $1 \mathrm{~Hz}, 36.8 \mathrm{~Hz}$, and $62.3 \mathrm{~Hz}$ are still unidentified.

\section{SUPPRESSION METHOD OF BEAM OSCILLATION}

Suppression of vertical vibration is more important than horizontal one due to its smaller emittance. Fortunately number of oscillation peaks in vertical direction are smaller than that of horizontal. The highest peak of $29.5 \mathrm{~Hz}$ and $58.9 \mathrm{~Hz}$ peak are the vibration propagated through the floor from water pump in machine room. These peaks are relatively easy to suppress. The cooling water pumps are on vibration proof bed. Most effective method is to improve this vibration proof bed to more effective one. Suppression of oscillation around 40 $\mathrm{Hz}$ is difficult because the vibration amplitude of magnet in that region is small. However if we can suppress 29.5 $\mathrm{Hz}$ and $58.9 \mathrm{~Hz}$, amplitude of beam oscillation decreases remarkably.

In horizontal direction the largest oscillation is around 83.5 Hz. This region is difficult to suppress if the betatron oscillation coincide with the vibration wavelength. For the suppression of cooling water originated oscillation, we need to improve the magnet structure, pipe arrangement and water pumps.

\section{CONCLUSION}

We measured the beam oscillations and magnet vibrations in the frequency rage below $100 \mathrm{~Hz}$. Most oscillation peaks observed in the frequency spectrum of an electron beam are resulting from magnet and girder vibration. Horizontal vibration of magnets is mainly induced by the water flow in magnets coil and vertical vibration is the results of propagation of vibration from cooling water pumps to magnets through floor and a girder. For the suppression of vertical magnet vibration, we should improve the vibration proof bed of cooling water pumps. For horizontal direction, we need to change the magnet and girder structure as well as make a very quiet flow of cooling water.

\section{ACKNOWLEDGEMENT}

We would like to thank Dr. S. Sasaki for giving us the information about button monitor.

\section{REFERENCES}

[1] SPring-8 Annual Report, 1999, p12.

[2] K.Hasegawa, Private communication. 